\title{
Pengaruh Solvabilitas dan Profitabilitas terhadap Penghindaran Pajak
}

\section{Adi Putra Wanda*, Elly Halimatusadiah}

Prodi Akuntansi, Fakultas Ekonomi dan Bisnis, Universitas Islam Bandung, Indonesia.

*adipwanda@gmail.com, elly.halimatusadiah@yahoo.com

\begin{abstract}
Tax storage is an effort to reduce the tax burden carried out by taxpayers in the scope of the tax laws carried out by utilizing weaknesses in tax laws and regulations to reduce the amount of tax debt. This study aims to determine the effect of the solvency and profitability of tax avoidance. Solvability is measured using a Debt To Asset Ratio (DAR). Profitability is measured using ROA (Returns On Assets). Tax avoidance is measured using CETR (Cash Effective Tax Rates). This research uses secondary data. The research method used in this study was descriptive with a quantitative approach. The population in this study is a manufacturing company from the industrial sector of consumer goods listed on the Indonesia Stock Exchange (IDX) for 4 periods, namely 2016-2019. The sample of this study used a purposive sampling method so that 21 sample companies were obtained. The hypothesis testing used in this study uses multiple regression analysis. The hypothesis test results show that solvency has a positive effect on tax avoidance, and profitability has a negative effect on tax avoidance. For further research purposes, it is recommended to use other factors considered to affect tax avoidance, such as company size, capital intensity,etc.
\end{abstract}

Keywords: Profitability, Solvency, Tax Avoidance.

\begin{abstract}
Abstrak. Penghindaran Pajak adalah usaha untuk meminimalkan beban pajak yang dilakukan oleh wajib pajak pada batas cakupan ketetapan perundang-undangan perpajakan yang dilaksanakan dengan menggunakan beberapa kelemahan pada undang-undang serta peraturan perpajakan guna mengurangi total pajak yang terutang. Penelitian ini tujuannya untuk memahami pengaruh solvabilitas dan profitabilitas pada penghindaran pajak. Solvabilitas diukur dengan memakai DAR (Debt To Asset Ratio). Pengukuran Profitabilitas dengan memanfaatkan ROA (Return On Asset). Pengukuran Penghindaran Pajak dengan memanfaatkan Cash Effective Tax Rate. Penelitian ini memanfaatkan data sekunder. Metode penelitian yang dipergunakan pada penelitian ialah metode kuantitatif dan deskriptif. Objek penelitian ini yaitu perusahaan manufaktur di industrì barang konsumsi yang tercatat di BEI selama 4 tahun yaitu 2016-2019. Sampel dalam penelitian ini menerapkan metode purposive sampling untuk mendapatkan sampel dari 21 perusahaan. Uji hipotesis yang dipergunakan pada penelitian ini memakai analisis regresi berganda. Hasil uji hipotesis membuktikan bahwa solvabilitas memberi pengaruh positif pada penghindaran pajak, serta profitabilitas memberi pengaruh negatif pada penghindaran pajak. Diberi saran agar mempelajari lebih lanjut dan memakai beberapa faktor lain yang dianggap memberi pengaruh pada penghindaran pajak, seperti intensitas modal dan ukuran perusahaan.
\end{abstract}

Kata Kunci: Penghindaran Pajak, Profitabilitas, Solvabilitas. 


\section{A. Pendahuluan}

Pajak memiliki peranan penting dalam pembangunan nasional. Sumber penerimaan negara yang utama bersumber dari pajak dengan menyumbang sekitar $70 \%$ dari semua pendapatan negara. Dengan adanya pajak kegiatan pembangunan nasional di berbagai bidang dapat dilaksanakan. Salah satu bentuk partisipasi warga negara dalam pembangunan nasional dengan patuh membayar pajak. Pembayaran pajak merupakan hak dan kewajiban warga negara dalam rangka berpartisipasi terhadap pembiayaan dan pembangunan negara. Kepatuhan wajib pajak yakni kondisi dimana wajib pajak menghitung, mendaftarkan diri, menyampaikan, serta membayar kewajiban perpajakannya lalu menyetorkan kembali surat setoran selaras dengan ketentuan yang berlaku tanpa adanya unsur paksaan (Aprebiyani, Nurhayati, \& Halimatusadiah, 2020:132).

Sistem akumulasi pajak yang berlaku di Indonesia ialah Self Assessment. Self assesment system ialah sebuah sistem akumulasi pajak dimana wajib pajak diberikan kewenangan dalam membayar, menghitung, atau memberitahukan sendiri jumlah pajaknya ke KPP maupun secara online melalui sistem yang telah tersedia dari pemerintah. Pada penerapan di kehidupan nyata masih terdapat beberapa Wajib Pajak yang melakukan tunggakan Pajak. Sebagaimana fenomena yang bersumber dari berita online detikfinance pada 02 Agustus 2019, Direktur Jenderal Pajak (Dirjen Pajak) Robert Pakpahan menyatakan bahwa Sektor manufaktur tumbuh negatif 2,6\% mapun menjadi lambat daripada periode yang sama tahun sebelumnya. Perkembangan negatif bidang manufaktur pun lebih besar diakibatkan oleh moderasi ataupun restitusi kegiatan impor. Hal tersebut terjadi di berbagai sub industri utama misal industri kimia, pertambangan, logam, dan minuman ataupun makanan, yang sebenarnya sub industri minuman atau makanan tidak menjadi lambat sebab sebagai sektor unggulan (sudah ekspor banyak). Kasus yang paling baru dimana perusahaan tembakau milik BAT dilaporkan oleh Lembaga Internasional Independen Tax Justice Network karena menghindari pajak di Indonesia melalui PT Bentoel Internasional Investama, serta menyebabkan negara merugi sebanyak US\$ 14 juta per tahun (Prima 2019).

Tax avoidance yaitu usaha menghindari pajak yang dilakukan dengan aman atau legal bagi wajib pajak sebab tidak melanggar peraturan perpajakan, di mana teknik dan metode yang dipergunakan cenderung menggunakan grey area yang ada pada undang-undang serta ketentuan perpajakan itu sendiri, guna mengurangi besaran pajak yang terutang (Pohan, 2014:23). Organisation for Economic Co-operation and Development memaparkan bahwa tax avoidance yaitu upaya wajib pajak memperkecil pajak terutang, walaupun usaha ini memungkinkan tidak bertentangan dengan hukum, tetapi sesungguhnya melanggar tujuan dibuatnya the spirit of the law.

Dari fenomena tersebut mendukung fakta bahwa penghindaran pajak akan muncul sebab masyarakat yang ahli pada sektor perpajakan bisa memanfaatkan celah dari ketentuan guna meminimalkan besaran pajak. Terdapat beberapa faktor yang bisa menjadi penyebab adanya Penghindaran Pajak yakni Profitabilitas dan Solvabilitas.

\section{B. Landasan Teori}

\section{Solvabilitas}

Menurut Darya (2019:144) mendefinisikan Solvabilitas sebagai daya perusahaan dalam membayar pinjaman dengan menggunakan seluruh kekayaan maupun kekayaan menjadi penjamin utang sebagai konsep dasar akuntansi. Sangatlah penting untuk mengetahui solvabilitas perusahaan agar paham terkait daya perusahaan dalam membayar seluruh hutang melalui total aktiva yang dimiliki yang mempengaruhi jenis laporan keuangan. Secara sistematis menurut Kasmir (2016: 156) Solvabilitas dapat diukur menggunakan rumus sebagai berikut:

$$
\text { Debt to Asset Ratio }=\frac{\text { Total Debt }}{\text { Total Assets }}
$$




\section{Profitabilitas}

Merupakan daya perusahaan mendapat keuntungan dalam kaitannya dengan penjualan, jumlah aktiva ataupun biaya sendiri. Sehingga bagi pemodal jangka panjang akan sangat mempunyai kepentingan dengan analisis profitabilitas ini seperti bagi shareholder akan mengetahui laba yang akan diterima berupa dividen (Sartono, 2015:122). Secara sistematis, menurut Sartono (2015:123) pengukuran Profitabilitas bisa memakai rumus seperti berikut:

$$
\text { Return on asset }=\frac{\text { Laba Setelah Pajak }}{\text { Total Aset }}
$$

\section{Penghindaran Pajak}

Menurut Rahayu (2010:147) mengemukakan bahwa Tax Avoidance sebagai cara memperkecil pajak yang masih pada batas ketetapan undang-undang perpajakan serta bisa dibetulkan khususnya melalui rencana perpajakan. Secara sistematis menurut Hanlon \& Heitzmen (2010) menyatakan bahwa salah satu cara perhitungan Tax Avoidance yang sering digunakan adalah Cash ETR dengan rumus sebagai berikut:

$$
\text { Cash ETR }=\frac{\text { Cash Tax Paid } i, t}{\text { Pre }- \text { tax Income } i, t}
$$

\section{Pembahasan dan Diskusi}

\section{Hasil Penelitian}

Penelitian ini dilaksanakan pada 21 perusahaan manufaktur sektor industri barang konsumsi yang tercatat di BEI selama tahun 2016-2019, sehingga jumlah unit analisis yang dipergunakan pada penelitian ini sejumlah 84 data.

Tingkat solvabilitas mempunyai skor tertinggi berada pada perusahaan Tunas Baru Lampung Tbk. (TBLA) dengan nilai 0,73 di tahun 2016 serta skor paling rendah berada pada perusahaan Industri Jamu dan Farmasi Sido Muncul Tbk. (SIDO) dengan skor 0,08 di tahun 2016 serta tahun 2017. Besarnya rata-rata nilai solvabilitas pada perusahaan manufaktur sektor industri barang konsumsi yang tercatat di BEI tahun 2016-2019 senilai 0,3618.

Tingkat profitabilitas tertinggi berada pada perusahaan Multi Bintang Indonesia Tbk. dengan skor 0,53 pada tahun 2017 dan nilai terendah berada pada perusahaan Budi Starch \& Sweetener Tbk. (BUDI) dengan nilai 0,01 pada tahun 2016 serta tahun 2018. Besarnya rata-rata nilai profitabilitas pada perusahaan manufaktur sektor industri barang konsumsi yang tercatat di BEI tahun 2016-2019 sebesar 0,1214.

Penghindaran pajak perusahaan manufaktur bidang industri barang konsumsi yang tercatat di BEI tahun 2016-2019 memiliki skor tertinggi pada perusahaan Campina Ice Cream Industry Tbk. (CAMP) dengan nilai 0,40 pada tahun 2017 dan nilai terendah berada pada perusahaan Budi Starch \& Sweetener Tbk. (BUDI) pada tahun 2018 serta perusahaan Tunas Baru Lampung Tbk. (TBLA) dengan nilai 0,03 pada tahun 2018 serta tahun 2019. Besarnya rata-rata nilai penghindaran pajak pada perusahaan manufaktur bidang industri barang konsumsi yang tercatat di BEI tahun 2016-2019 sebesar 0,2278.

Dari hasil olah data dengan memakai SPSS versi 23, didapat hasil regresi linear berganda dalam tabel 1 . 
Tabel 1. Hasil Regresi Linear Berganda

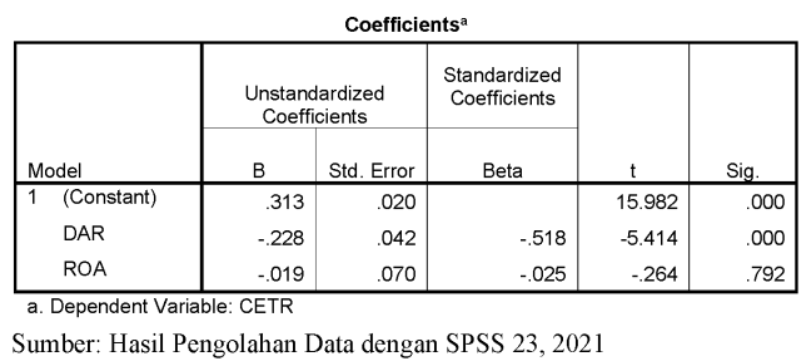

Pada tabel tersebut bisa diketahui skor konstanta dan koefisien regresi, dengan begitu bisa dibuat persamaan regresi linier berganda yaitu:

$$
P P=0,313-0,228 S V-0,019 P F+e
$$

Berlandaskan persamaan regresi tersebut, bisa dijelaskan pernyataan seperti berikut:

1. Didapat angka konstanta (a) pada persamaan regresi di atas senilai 0,313. Bila tidak terdapat perubahan solvabilitas ataupun profitabilitas (bernilai nol) maka penghindaran pajak akan memiliki nilai 0,313.

2. Diperoleh nilai koefisien regresi solvabilitas nilainya negatif senilai $-0,228$. Bila variabel solvabilitas turun sebanyak satu satuan, maka penghindaran pajak akan naik senilai 0,228 dengan anggapan variabel lain tetap.

3. Diperoleh angka koefisien regresi profitabilitas mempunyai nilai negatif senilai $-0,019$. Bila variabel profitabilitas naik senilai satu satuan, maka penghindaran pajak akan turun senilai 0,019 dengan anggapan variabel lain tetap.

Dibawah ini merupakan hasil Uji statistik F yang membuktikan dampak variabel independen terhadap variabel terikat secara bersamaan.

Tabel 2. Nilai Uji F

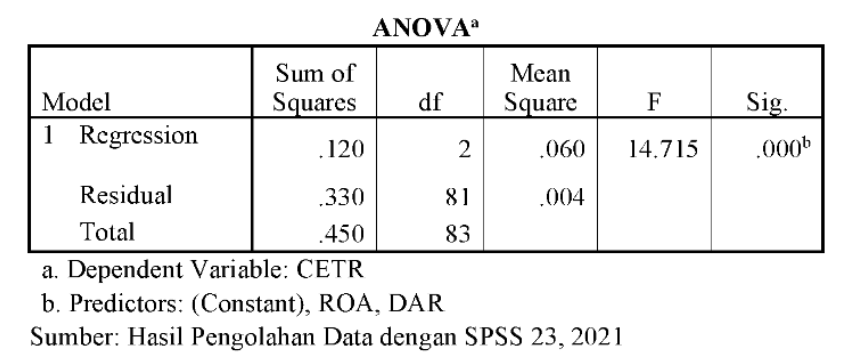

Tabel 2 memperlihatkan bahwa angka sig $\mathrm{F}$ diperoleh tingkat signifikan sebanyak 0,000 . Hasil dari tingkat signifikan $<0,05$ yakni 0,000 yang berarti menerima $\mathrm{H}_{\mathrm{O}}$ atau menerima Ha, dengan demikian bisa dianggap bahwa profitabilitas ataupun solvabilitas memberi pengaruh secara bersamaan maupun bermakna pada penghindaran pajak perusahaan.

Tabel hasil Uji t yang membuktikan pengaruh setiap variabel bebas pada variabel dependen yaitu. 
Tabel 3. Nilai Uji $\mathrm{t}$

\begin{tabular}{|c|c|c|c|c|c|}
\hline \multirow[b]{3}{*}{ Model } & \multicolumn{3}{|c|}{ Coefficients $^{a}$} & \multirow[b]{3}{*}{1} & \multirow[b]{3}{*}{ Sig. } \\
\hline & \multicolumn{2}{|c|}{$\begin{array}{l}\text { Unstandardized } \\
\text { Coefficients }\end{array}$} & \multirow{2}{*}{$\begin{array}{c}\text { Standardized } \\
\text { Coefficients } \\
\text { Bcta } \\
\end{array}$} & & \\
\hline & B & $\begin{array}{l}\text { Sid. } \\
\text { Error }\end{array}$ & & & \\
\hline 1 (Constant) & .313 & .020 & & 15.982 & .000 \\
\hline DAR & -.228 & .042 & -.518 & -5.414 & .000 \\
\hline ROA & -.019 & .070 & -.025 & -.264 & .792 \\
\hline
\end{tabular}

1. Dari hasil pengujian tersebut, angka signifikansi variabel solvabilitas adalah 0,000 . Angka itu dibawah taraf sig $(\alpha=5 \%)$ yakni $0,000 \quad 0,05$. Berdasarkan hasil analisis perbandingan nilai, hasil uji H1 diterima yang menunjukkan bahwa solvabilitas dan penghindaran pajak memiliki pengaruh yang signifikan.

2. Dari hasil uji itu bisa diketahui bahwa angka signifikansi variabel Profitabilitas adalah 0,792 . Angka itu diatas taraf signifikansi $(\alpha=5 \%)$ yaitu $0,7920,05$. Berdasarkan hasil analisis perbandingan nilai, hasil uji menolak $\mathrm{H} 2$ yang berarti tidak ada pengaruh bermakna antara profitabilitas dan penghindaran pajak.

Uji koefisien determinasi dilakukan guna melihat persentase pengaruh variabel independen pada variabel terikat.

Tabel 4. Koefisien Determinasi Simultan

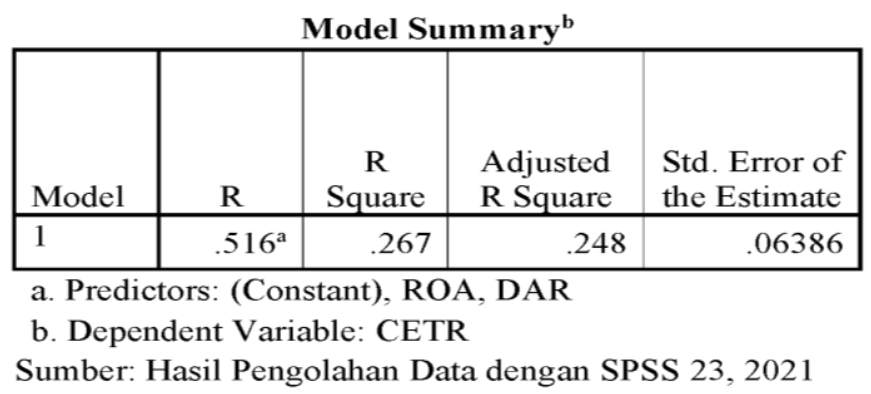

Dari hasil uji yang sudah diambil, skor R-squared yang dihitung dengan SPSS di atas adalah $0,267=26,7 \%$. Angka koefisien determinasi mendekati 0 , yang berarti variabel Solvabilitas dan Profitabilitas dapat menerangkan variabel Penghindaran Pajak sebesar 26,7\%. Sementara, skor sisa senilai 73,3\% mendapat pengaruh dari faktor lain yang tidak dibahas.

Agar melihat pengaruh dari setiap variabel bebas terhadap variabel dependen yakni dengan uji koefisien determinasi parsial pada tabel 5:

Tabel 5. Koefisien Determinasi Parsial

\begin{tabular}{|c|c|c|}
\hline \multicolumn{3}{|c|}{ Coefficients $^{\mathbf{a}}$} \\
\hline & $\begin{array}{l}\text { Standardized } \\
\text { Coefficients }\end{array}$ & Correlations \\
\hline Model & Beta & Zero-order \\
\hline 1 (Constant) & & \\
\hline DAR & -.518 & -.516 \\
\hline ROA & -.025 & .033 \\
\hline
\end{tabular}

a. Dependent Variable: CETR

Sumber: Hasil pengolahan SPSS versi 23, 2021 


$$
\begin{aligned}
\text { Solvabilitas } & =-0,518 \times-0,516 \\
& =0,2673(26,73 \%) \\
\text { Profitabilitas } & =-0,025 \times 0,033 \\
& =-0,000825(-0,08 \%)
\end{aligned}
$$

Berlandaskan hasil perhitungan tersebut bisa dilihat bahwa variabel Solvabilitas menghasilkan pengaruh pada Penghindaran Pajak senilai 26,73\%, sedangkan variabel Profitabilitas menghasilkan pengaruh pada Penghindaran Pajak senilai -0,08\%.

\section{Pengaruh Solvabilitas Terhadap Penghindaran Pajak}

Berlandaskan hasil uji hipotesis dan uji t angka signifikansi solvabilitas senilai 0.000 , bila dilakukan perbandingan dengan $\alpha=0,05$, maka maka angka signifikan dibawah $\alpha(\operatorname{Sig} \leq \alpha)$, yakni $, 000 \leq 0,05$. Angka itu membuktikan bahwa hipotesis pada penelitian ini diterima, sehingga dapat dikatakan bahwa solvabilitas memiliki pengaruh terhadap penghindaran pajak. Berdasarkan tabel statistik deskriptif rata-rata umum perusahaan memiliki nilai agresivitas bernilai 0.23 yaitu dibawah 0.25 yang berarti perusahaan rata-rata melakukan penghindaran pajak. Sehingga perusahaan dengan tingkat solvabilitas yang rendah cenderung mempunyai tingkat penghindaran pajak yang tinggi yang artinya perusahaan itu kian besar kemungkinan untuk menghindari pajak karena pendanaan perusahaan tidak dilakukan dengan cara berhutang melainkan menggunakan dana yang berasal dari modal sendiri. ini diperkuat dengan penelitian sebelumnya dari Angelina (2019) didapati hasil bahwa Solvabilitas memberi pengaruh pada Tax Avoidance dan Putri (2019) memaparkan bahwa Solvabilitas (DAR) mempengaruhi Tax Avoidance.

\section{Pengaruh Profitabilitas Terhadap Penghindaran Pajak}

Berlandaskan hasil uji hipotesis dan uji t didapat angka signifikansi profitabilitas senilai 0,792, bila dilakukan perbandingan dengan $\alpha=0,05$, maka angka signifikansi diatas $\alpha(\operatorname{Sig} \geq \alpha)$, yaitu $0,792 \geq 0,05$. Angka itu membuktikan bahwa hipotesis pada penelitian ini ditolak, maka bisa dinyatakan bahwa profitabilitas tidak memberi pengaruh pada penghindaran pajak. Dari hasil penelitian bisa dikategorikan bahwa perusahaan manufaktur sektor barang konsumsi dikatakan baik atau tingginya kemampuan untuk menghasilkan laba, hal ini didukung dengan hasil dari tabel statistik deskriptif profitabilitas pada tahun 2016-2019 yang menyatakan bahwa tingkat ROA mempunyai mean senilai 0,1214 ataupun $12,14 \% \geq 5,98 \%$. Hasil penelitian ini selaras dengan penelitian dari Aulia \& Mahpudin (2020) memaparkan bahwa variabel profitabilitas tidak mempengaruhi tax avoidance, serta penelitian Ardianti (2020) pun memberikan temuan yang sama yakni Profitabilitas (ROA) tidak memberi pengaruh pada Tax Avoidance.

\section{Kesimpulan}

Berlandaskan penjelasan di penelitian ini, maka bisa diambil kesimpulan yaitu:

Hasil dari pengujian hipotesis menunjukkan bahwa tingkat Solvabilitas mempengaruhi penghindaran pajak di Perusahaan Manufaktur Sektor Industri Barang Konsumsi yang tercatat di BEI tahun 2016-2019.

Hasil dari pengujian hipotesis membuktikan bahwa tingkat profitabilitas tidak memberi pengaruh pada penghindaran pajak di Perusahaan Manufaktur Sektor Industri Barang Konsumsi yang tercatat di BEI tahun 2016-2019.

\section{Daftar Pustaka}

[1] Angelina, V.M. 2019. "Pengaruh Solvabilitas, Pertumbuhan Penjualan, Dan Kepemilikan Institusional Terhadap Tax Avoidance Yang Dimoderasi Oleh Profitabilitas". Undergraduate thesis. Universitas Kristen Maranatha.

[2] Aprebiyani, D.F., Nurhayati, N., \& Halimatusadiah, E. 2020. "Pengaruh Pengetahuan Sanksi Pada Dan Penerapan E-Filing Terhadap Kepatuhan Wajib Pajak". Prosiding Akuntansi Volume 6, No. 1.

[3] Ardianti, P.N.H. 2020. "Profitabilitas, Leverage, dan Komite Audit Pada Tax Avoidance". 
Jurnal Akuntansi Universitas Udayana Vol.26.3.Maret (2019): 2020-2040.

[4] Aulia, Ismiani \& Mahpudin, Endang. 2020. "Pengaruh profitabilitas, leverage, dan ukuran perusahaan terhadap tax avoidance". Jurnal Akuntansi dan Keuangan Vol 17, No 2 (2020) pISSN: 0216-7743 eISSN: 2528-1135

[5] Darya, I.G.P. 2019. “Akuntansi Manajemen". Ponorogo: Uwais Inspirasi Indonesia.

[6] Hanlon, Michelle \& Heitzman, Shane. 2010. "A review of tax research". Journal of Accounting and Economics, 50 (40). 127 - 178.

[7] Kasmir. 2016. “Analisis Laporan Keuangan Edisi 1 Cetakan Kesembilan”. Jakarta: PT. Raja Grafindo Persada.

[8] Pohan, C.A. 2014. "Manajemen Perpajakan : Strategi Perencanaan Pajak \& Bisnis (Edisi Revisi)". Jakarta: Gramedia Pustaka Utama.

[9] Prima, Benedicta (Ed.). 2019. "Tax Justice laporkan Bentoel lakukan penghindaran pajak, Indonesia rugi US\$ 14 juta”, tersedia di https://nasional.kontan.co.id [15/10/2020]

[10] Putri, N.M. 2019. "Pengaruh Profitabilitas, Likuiditas, Solvabilitas Dan Ukuran Perusahaan Sebagai Variabel Moderasi Terhadap Tax Avoidance Pada Perusahaan Sub Sektor Property Dan Real Estate Yang Terdaftar Di Bursa Efek Indonesia Tahun 2014-2018”. Skripsi. Universitas Gunadarma.

[11] Rahayu, S.K. 2010. "PERPAJAKAN INDONESIA : Konsep dan Aspek Formal". Yogyakarta: Graha Ilmu.

[12] Simorangkir, Eduardo. 2019. "Penerimaan Pajak 2019 Melambat, Ini Daftar Sektor Usaha yang Loyo", tersedia di https://finance.detik.com [14/10/2020] 